\title{
Hubungan antara Berat Badan Lahir Bayi dengan Ruptur Perineum pada Primipara
}

\author{
Russiska $^{1}$, Susan Yuliyantika ${ }^{2}$, Merissa Laora Heryanto ${ }^{3}$ \\ Email: russiska88@gmail.com ${ }^{1}$,yuliyantika29@gmail.com ${ }^{2}$, merissalaora@gmail.com ${ }^{3}$ \\ Program Studi Kebidanan, Sekolah Tinggi Ilmu Kesehatan Kuningan, Indonesia \\ Jl. Lingkar Kadugede No 2 Kuningan \\ Telp. (0232) 875847
}

\begin{abstract}
Abstrak
Angka Kematian Ibu (AKI) di Indonesia sekitar 90\% terjadi pada saat persalinan. di Indonesia hingga tahun 2018 Angka Kematian Ibu masih tetap tinggi di 305 per 1000 kelahiran hidup ${ }^{[1]}$. Hal ini disebabkan oleh pendarahan pasca persalinan akibat dari beberapa faktor seperti atonia uteri dan ruptur perineum. Tujuan penelitian mengetahui hubungan antara berat badan lahir bayi dengan ruptur perineum pada Primipara di Puskesmas Japara Kabupaten Kuningan tahun 2019. Metode penelitian adalah analitik dengan pendekatan cross sectional, pengambilan sampel dengan teknik total sampling dengan jumlah 52 ibu bersalin. Instrumen yang digunakan menggunakan lembar cheklist dan analisis yang digunakan menggunakan Spearman Rank. Berdasarkan hasil penelitian analisis univariat, sebagian besar ibu melahirkan bayi dengan berat badan lahir normal yaitu sekitar 59,6\%, sedangkan sebagian besar ibu mengalami ruptur perineum yaitu sekitar $51,9 \%$. Hasil analisis bivariat menunjukkan nilai $(p=0,09)$ hal ini menunjukan bahwa terdapat hubungan yang signifikan antara berat badan lahir bayi dengan ruptur perineum pada ibu bersalin. Disimpulkan bahwa terdapat hubungan yang signifikan antara berat badan lahir bayi dengan ruptur perineum pada ibu bersalin. Diharapkan bidan selalu melakukan penatalaksanaan persalinan yang sesuai dengan standart asuhan persalinan normal saat melakukan persalinan dan mengajarkan pada ibu hamil cara pemijatan perineum.
\end{abstract}

Kata Kunci: berat badan lahir bayi; ruptur perineum; ibu bersalin.

\begin{abstract}
The Maternal Mortality Rate (MMR) in Indonesia is around $90 \%$ at the time of delivery. in Indonesia until 2018 the Maternal Mortality Rate is still high at 305 per 1000 live births ${ }^{[1]}$. This is caused by postpartum bleeding due to several factors such as uterine atony and perineal rupture. The research objective was to determine the relationship between birth weight of infants and perineal rupture in Primipara at Japara Public Health Center, Kuningan Regency in 2019. The research method was analytic with a cross sectional approach, sampling with a total sampling technique with a total of 52 mothers giving birth. The instrument used was a checklist sheet and the analysis used Spearman Rank. Based on the results of the univariate analysis study, most mothers gave birth to babies with normal birth weight, namely around $59.6 \%$, while most of the mothers experienced perineal rupture, namely around $51.9 \%$. The results of the bivariate analysis showed a value $(p=0.09)$, this indicated that there was a significant relationship between birth weight of infants and perineal rupture in mothers who gave birth. It was concluded that there was a significant relationship between birth weight of infants and perineal rupture in mothers who gave birth. It is hoped that midwives will always carry out labor management in accordance with the standards of normal delivery care when giving birth and teach pregnant women how to massage the perineum.
\end{abstract}

Keywords: birth weight of the baby; perineal rupture; mother in labor. 


\section{Pendahuluan}

Angka Kematian Ibu (AKI) di Indonesia sekitar $90 \%$ terjadi pada saat persalinan. Hal ini disebabkan oleh pendarahan pasca persalinan akibat dari beberapa faktor seperti atonia uteri dan ruptur perineum. Persalinan seringkali mengakibatkan robeknya perineum atau rupture perineum. Rupture perineum merupakan robekan yang terjadi pada perineum sewaktu proses persalinan ${ }^{[2]}$. Kejadian ruptur perineum pada ibu bersalin didunia pada tahun 2015 terdapat 2,5 juta kasus, di mana angka ini diperkirakan akan mencapai 6,3 juta pada tahun 2050. Di benua Asia sendiri 50\%, ibu bersalin mengalami ruptur perineum ${ }^{[3]}$. Rupture perineum dapat terjadi karena beberapa faktor yaitu faktor maternal, faktor janin, dan faktor penolong. Ruptur perineum juga dapat terjadi karena ruptur spontan maupun ruptur di sengaja (episiotomi). Berat badan bayi lahir dapat berpengaruh pada peregangan perineum sehingga pada perineum mudah terjadi ruptur. Berat badan lahir yang lebih dari 4000 gram dapat meningkatkan risiko terjadinya ruptur perineum hal ini disebabkan karena perineum tidak cukup kuat menahan regangan kepala bayi dengan berat badan bayi yang besar ${ }^{[4]}$.

$$
\text { Menurut } \text { penelitian }^{[5]} \text {, }
$$
didapatkan ada hubungan antara berat lahir bayi dengan kejadian ruptur perineum di mana semakin besar berat lahir bayi semakin tinggi tingkat ruptur perineum pada ibu primipara. Persalinan dengan ruptur perineum apabila tidak ditangani secara efektif menyebabkan perdarahan dan infeksi menjadi lebih berat, serta pada jangka waktu panjang dapat mengganggu ketidak nyamanan ibu dalam hal hubungan seksual ${ }^{[6]}$.

Berdasarkan hasil studi pendahuluan di Puskesmas Japara Kabupaten Kuningan, pada bulan April 2020 didapatkan terdapat sejumlah 5 ibu primigravida yang mengalami ruptur perineum pada saat proses persalinan. Salah satu upaya yang dapat dilakukan petugas untuk mencegah terjadinya ruptur perineum adalah dengan melakukan penatalaksanaan persalinan yang sesuai dengan standart asuhan persalinan normal (60 langkah APN) untuk mengontrol lahirnya kepala, bahu, lengan dan kaki dan akan memberikan waktu bagi kulit untuk meregang sehingga mengurangi kemungkinan ruptur perineum ${ }^{[7]}$.

\section{Metode Penelitian}

Metode penelitian ini adalah analitik dengan pendekatan cross sectional, populasi dalam penelitian ini adalah ibu bersalin primipara, pengambilan sampel dengan teknik total sampling sampling dengan jumlah 52 ibu bersalin. Penelitian mempunyai 2 variabel. variabel bebas dalam penelitian ini adalah berat badan lahir bayi sedangkan variabel terikatnya adalah ruptur perineum. Instrumen yang digunakan menggunakan lembar cheklist. Data yang digunakan dalam penelitian ini adalah data primer dari hasil observasi ibu bersalin secara langsung dan analisis yang digunakan menggunakan Spearman Rank. 
Jurnal Kebidanan Harapan Ibu Pekalongan

\section{Hasil dan Pembahasan}

Hasil penelitian

Tabel 1 Distribusi Berat Badan Lahir Bayi

\begin{tabular}{cccc}
\multicolumn{2}{c}{ Bayi } & & \\
\hline No & $\begin{array}{c}\text { Berat Badan Lahir } \\
\text { Bayi }\end{array}$ & F & \% \\
\hline 1 & Normal & 31 & $59,6 \%$ \\
\hline 2 & BBLR dan Besar & 21 & $40,4 \%$ \\
\hline & Jumlah & $\mathbf{5 2}$ & $\mathbf{1 0 0 \%}$ \\
\hline
\end{tabular}

Berdasarkan Tabel di atas dari 52 responden sebagian besar 31 responden $\quad(59,6 \%)$ melahirkan berat badan lahir bayi normal, 21 responden $(40,4 \%)$ berat badan lahir bayi rendah dan besar.
Tabel 2 Distribusi Ruptur Perineum

\begin{tabular}{cccc}
\hline No & Ruptur Perineum & F & \% \\
\hline 1 & Tidak Ruptur & 25 & $48,1 \%$ \\
\hline 2 & Ruptur & 27 & $51,9 \%$ \\
\hline & Jumlah & $\mathbf{5 2}$ & $\mathbf{1 0 0 \%}$ \\
\hline
\end{tabular}

Berdasarkan Tabel diatas dari 52 responden sebagian besar responden mengalami ruptur perineum sebanyak 27 responde $(51,9 \%)$ dan responden yang tidak mengalami ruptur perineum terdapat 25 responden $(48,1 \%)$.

Tabel 3 Hubungan Antara Berat Badan Lahir Bayi Dengan Ruptur Perineum

\begin{tabular}{|c|c|c|c|c|c|c|c|c|}
\hline \multirow{3}{*}{ No } & \multirow{3}{*}{$\begin{array}{c}\text { Berat Badan } \\
\text { Lahir Bayi }\end{array}$} & \multicolumn{4}{|c|}{ Ruptur Perineum } & \multirow{2}{*}{\multicolumn{2}{|c|}{ Total }} & \multirow{3}{*}{ P-Value } \\
\hline & & \multicolumn{2}{|c|}{ Tidak Ruptur } & \multicolumn{2}{|c|}{ Ruptur } & & & \\
\hline & & $\mathbf{F}$ & $\%$ & $\mathbf{F}$ & $\%$ & $\mathbf{F}$ & $\%$ & \\
\hline 1 & Normal & 14 & 45,1 & 17 & 54,9 & 31 & 100 & \multirow{2}{*}{0.009} \\
\hline 2 & BBLR dan Besar & 11 & 52,3 & 10 & 47,7 & 21 & 100 & \\
\hline
\end{tabular}

Berdasarkan data diatas diketahui bahwa dari 31 responden yang melahirkan berat badan bayi normal sebagian besar mengalami ruptur perineum 17 responden $(54,9 \%)$ dan tidak terjadi ruptur perineum 14 responden $(45,1 \%)$. Dari 21 responden yang melahirkan dengan berat badan bayi lahir rendah dan besar sebagian tidak mengalami ruptur perineum 11 responden $\quad(52,3 \%), \quad$ yang mengalami ruptue perineum 10 responden $(47,7 \%)$.

Hasil uji statistik diperoleh nilai p $(0,009)$ untuk analisis hubungan antara berat badan lahir bayi dengan ruptur perineum, maka dapat dikatakan bahwa Ho ditolak artinya terdapat hubungan yang signifikan antara berat badan lahir bayi dengan ruptur perineum.

\section{Pembahasan}

Berdasarkan dari hasil penelitian ibu bersalin sebagian besar melahirkan bayi dengan berat badan lahir normal Bayi baru lahir normal adalah bayi baru lahir dari kehamilan yang aterm (37-42 minggu) dengan berat badan lahir 2500-4000 gram. Faktor yang mempengaruhi berat bayi lahir merupakan hasil interaksi dari berbagai faktor melalui suatu proses yang berlangsung selama berada dalam kandungan ${ }^{[8]}$. Menurut peneliti, berat bayi lahir di pengaruhi oleh status gizi ibu saat hamil. Status gizi ibu pada waktu pembuahan dan selama hamil dapat mempengaruhi pertumbuhan janin yang sedang dikandung Selain itu gizi ibu hamil menentukan berat bayi yang dilahirkan, maka 
Jurnal Kebidanan Harapan Ibu Pekalongan

pemantauan gizi ibu hamil sangatlah penting dilakukan.

Berdasarkan dari hasil penelitian sebagian besar ibu bersalin mengalami ruptur perineum, hal ini terjadi karena pasien tidak mampu berhenti mengejan, partus diselesaikan secara tergesa-gesa dengan dorongan fundus yang berlebihan, edema dan kerapuhan pada perineum, varikositas vulva yang melemahkan jaringan perineum, arcus pubis sempit dengan pintu bawah panggul yang sempit pu;a sehingga menekan kepala bayi ke arah posterior, Peluasan episiotomi, bayi yang besar, posisi letak bayi yang abnormal ${ }^{[9]}$.

Dari hasil uji bivariat terdapat hubungan antara berat badan lahir bayi dengan ruptur perineum. Hal ini sejalan dengan teori Cuningham $^{[4]}$, bahwa penyebab terjadinya ruptur perineum dapat dilihat dari dua faktor yaitu faktor maternal dan janin Faktor janin yang menjadi penyebab terjadinya ruptur perineum adalah berat badan lahir, posisi kepala yang abnormal, distosia bahu, kelainan bokong dan lain-lain. Berat badan lahir yang lebih dari 4000 gram dapat meningkatkan resiko terjadinya ruptur perineum hal ini disebabkan oleh karena perineum tidak cukup kuat menahan regangan kepala bayi dengan berat badan bayi yang besar $^{[4]}$.

Upaya pencegahan terjadinya ruptur perineum. Ruptur perineum dapat di hindari dengan cara pemijatan perineum yang dilakukan beberapa minggu sebelum bersalin untuk melemaskan otot-otot disekitar perineum menjadi lentur dan lebih meregang pada saat melahirkan, lakukan senam kegel untuk mencegah lemahnya sfingter uretra atau otot yang digunakan untuk berkemih dan nutrisi bagi ibu juga sangat diperlukan untuk membantu mengelastisitaskan kulit agar perineum dapat meregang selama melahirkan ${ }^{[10]}$.

\section{Kesimpulan}

Sebagian besar ibu bersalin di Puskesmas Japara Kabupaten Kuningan melahirkan bayi dengan berat badan lahir bayi normal 31 responden $(59,6 \%)$ dan sebagian besar mengalami ruptur perineum 27 responden $(51,9 \%)$. Terdapat hubungan yang signifikan antara berat badan lahir bayi dengan ruptur perineum dengan nilai $\mathrm{p}$ $(0,009)$.

\section{Daftar pustaka}

[1] Riset Kesehatan Dasar, Badan Penelitian dan Pengembangan Kesehatan Kementerian RI, Jakarta: Riskesdas, 2018.

[2] Wiknosastro, G.H, Ilmu Kebidanan (Edisi 4), Jakarta: Yayasan Bina Pustaka Sarwono Prawirohardjo, 2012.

[3] Survei Demografi Kesehatan Indonesia, Data Angka Kematian Ibu Jawa Barat, Bandung: Dinkes Jabar, 2016.

[4] Shofiyani, Hubungan Berat Badan Bayi Baru Lahir dengan Ruptur Perineum Spontan pada Penatalaksanaan Kala II Persalinan Normal, Skripsi, Ponorogo: Publikasi Universitas Muhammadiyah Ponorogo, 2013.

[5] Syarifah, Noviatri, Hubungan Berat Bayi Lahir dengan Kejadian Ruptur Perineum pada Persalinan Normal Primipara di RSUD Dr. Soedirman, Skripsi, Kebumen: Publikasi STIKes Aisyiah Yogyakarta, 2014. 
Jurnal Kebidanan Harapan Ibu Pekalongan

[6] Rosdiana, Faktor-Faktor yang Mempengaruhi Terjadinya Ruptur Perineum Pada Ibu Bersalin Normal di Puskesmas PONED Darul Imarah Aceh, Aceh: Jurnal STIKes U'Budiyah, 2015.

[7] UPTD Puskesmas Japara, Rekapitulasi Laporan Tahunan, Japara: Puskesmas Japara, 2019.

[8] Saifudin, AB, Buku Acuan Nasional Pelayanan Kesehatan Maternal dan Neonatal, Jakarta: YBP-SP, 2012.

[9] Oxorn, H, Wiliam, R, Forte, Ilmu Kebidanan, Patologi \& Fisiologi Persalinan, Yogyakarta: Yayasan Essentia Medika (YEM), 2010.

[10] Yudit, Hubungan antara Berat Badan Bayi Lahir dengan Ruptur Perineum Persalinan Pervaginam pada Primipara di Ruang Bersalin RSUD Prof. DR. R.D. Kandou Manado, Manado: Jurnal e-Biomedik (eBM), Volume 1, Nomor 1, 2013. 